\title{
National Ignition Facility SubSystem Design Requirements Beam Control \& Laser Diagnostics SSDR 1.7
}

\author{
E. Bliss
}

November 1, 1996

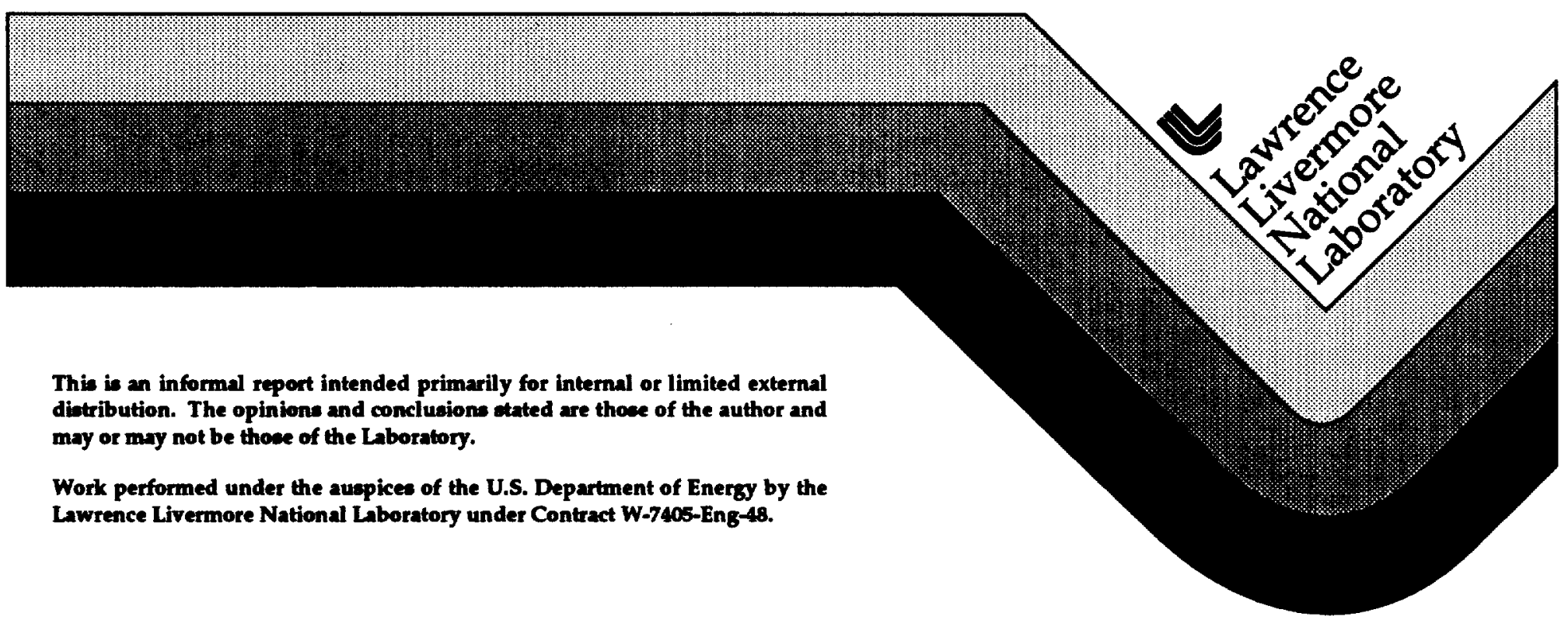




\section{DISCLAIMER}

This document was prepared as an account of work sponsored by an agency of the United States Government. Neither the United States Government nor the University of California nor any of their employees, makes any warranty, express or implied, or assumes any legal liability or responsibility for the accuracy, completeness, or usefulness of any information, apparatus, product, or process disclosed, or represents that its use would not infringe privately owned rights. Reference herein to any specific commercial product, process, or service by trade name, trademark, manufacturer, or otherwise, does not necessarily constitute or imply its endorsement, recommendation, or favoring by the United States Government or the University of California. The views and opinions of authors expressed herein do not necessarily state or reflect those of the United States Government or the University of California, and shall not be used for advertising or product endorsement purposes.

This report has been reproduced directly from the best available copy.

Available to DOE and DOE contractors from the Office of Scientific and Technical Information

P.O. Box 62, Oak Ridge, TN 37831

Prices available from (615) 576-8401, FTS 626-8401

Available to the public from the

National Technical Information Service

U.S. Department of Commerce

5285 Port Royal Rd.,

Springfield, VA 22161 


\section{National Ignition Facility \\ Subsystem Design Requirements \\ Beam Control \& Laser Diagnostics \\ SSDR 1.7 \\ Revision B \\ I November, 1996}

Prepared and Reviewed by:

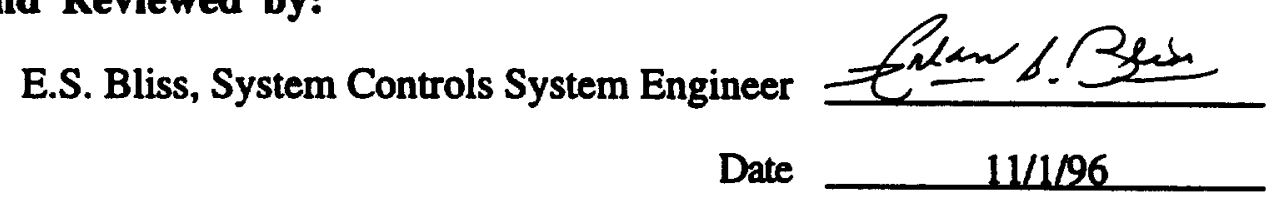

Reviewed by:

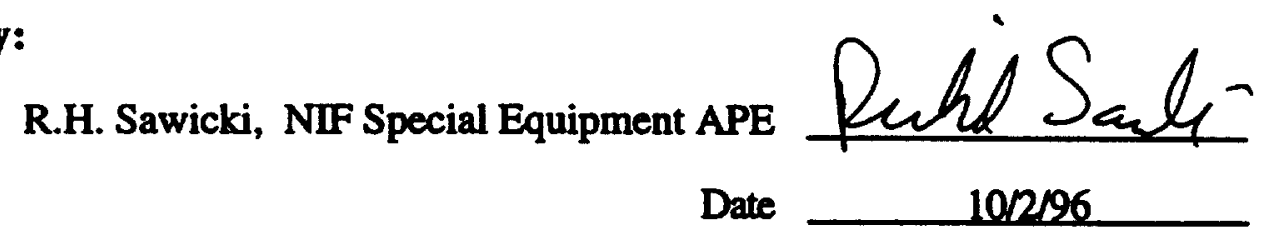

Engineering Review Board Approval:

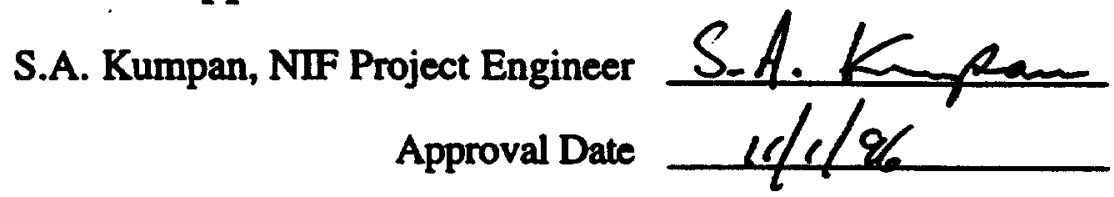




\section{Table of Contents}

\begin{tabular}{ll} 
Paragraph & Title \\
\hline 1.0 & Scope \\
2.0 & Applicable Documents \\
2.1 & Applicable NIF Documents \\
2.1 .1 & Applicable NIF Project Documents \\
2.1 .2 & Applicable NIF Drawings \\
2.1 .3 & Interface Control Documents \\
2.2 & Applicable US Government Codes and Standards \\
2.2 .1 & DOE Orders \\
2.2 .2 & Other Government Regulations \\
2.3 & Applicable National Codes and Standards \\
2.4 & Applicable LLNL Standards \\
3.0 & Subsystem Description and Characteristics \\
3.1 & Subsystem Definition \\
3.1 .1 & Subsystem Description \\
3.1 .2 & Subsystem Functions \\
3.1 .3 & Subsystem Diagrams \\
3.1 .3 .1 & System Operating Modes \\
3.1 .4 & Interfaces \\
3.1 .5 & Beam control \& laser diagnostics subsystem components \\
3.2 & Requirements and Verification \\
3.2 .1 & Performance Characteristics \\
3.1 .1 .1 & Beam Control Requirements \\
3.1 .1 .1 .01 & Adjust pulse timing \\
3.2 .1 .1 .02 & Adjust beam intensity \\
3.2 .1 .1 .03 & Identify beam shaper/apodizer center \\
3.2 .1 .1 .04 & Adjust beam center \\
3.2 .1 .1 .05 & Adjust beam rotation \\
3.2 .1 .1 .06 & Provide pinhole centering \\
3.2 .1 .1 .07 & Correct Wavefront Errors \\
3.2 .1 .1 .08 & Provide target position reference \\
3.2 .1 .1 .09 & Provide beam positioning \\
3.2 .1 .1 .10 & Adjust beam focus \\
3.2 .1 .1 .11 & Fine tune frequency conversion \\
3.2 .1 .2 & Laser Shot Diagnostics \\
3.2 .1 .2 .1 & Measure beam energy \\
3.2 .1 .2 .2 & Measure beam power \\
3.2 .1 .2 .3 & Measure prepulse intensity \\
3.2 .1 .2 .4 & Measure pulse spot size and smoothness \\
3.2 .1 .2 .5 & Measure beam wavefront \\
3.2 .1 .2 .6 & Image beam in FCC plane \\
3.2 .1 .3 & Detect optical damage \\
3.2 .1 .4 & Cleanliness \\
3.2 .1 .4 .1 & Internal metal component cleanliness \\
3.2 .1 .4 .2 & Assembly cleanliness \\
3.2 .1 .4 .3 & External surface cleanliness \\
3.2 .1 .5 & Shot turn-around time \\
3.2 .1 .6 & Experiment Compatibility \\
3.2 .1 .6 .1 & Accomodate classified experiments \\
3.2 .1 .6 .2 & Future Upgrades for Other Users \\
3.2 .1 .6 .2 .1 & Future Additional Target Chamber \\
&
\end{tabular}




\section{Table of Contents}

Paragraph

3.2.1.6.2.2

3.2.1.6.2.3

3.2 .2

3.2.2.1

3.2.2.1.1

3.2.2.1.2

3.2.2.2

3.2.2.2.1

3.2.2.3

3.2.3

3.2.3.1

3.2.3.2

3.2.3.3

3.2.3.4

3.2.3.5

3.2.3.6

3.2 .4

3.2.4.1

3.2.4.2

3.2 .4 .3

3.2.4.4

3.3

3.3.01

3.3.01.02

3.3.02

3.3.03

3.3.03.1

3.3.03.2

3.3.03.3

3.3.03.4

3.3.05

3.3.05.1

3.3.05.2

3.3 .07

3.3 .08

3.3 .09

3.3.10

3.3.11

3.3.12

3.3.13

3.4

3.4.1

3.4 .2

4.0

4.1

\section{Title}

Radiation Effects Testing Capability

Other User Needs

Physical Characteristics

General Arrangement

Beam Control \& Diagnostics Subsystem Architecture

General Arrangement Drawings

Beam Control \& Diagnostics Subsystem General Configuration

Number of total beams

Isolation and Grounding

Reliability, Availability, Maintainability

Lifetime

Replaceability

Inherent Availability

Reliability

Maintainability

Recovery From abnormal events

Environmental

Ambient Temperature/Humidity

Ambient Cleanliness

Ambient Vibration Environment

Back-Reflected Light

Design and Construction

Hazard Classification

Natural Hazards Classification

Radiation Protection

Safety

Life Safety

Laser Safety

Occupational Safety

Fail-Safe Design

Environmental Protection Requirements

Waste Management

Effluents

Future Modifications and Upgrades

Decontamination and Decommissioning

Human Factors

Interchangeability

Documentation and Records

Design Processes

Supervisory Software Access to Distributed Control Points

Logistics

Spare Equipment

Maintenance Equipment

Quality Assurance

Q-Level Assigned 


\subsection{Scope}

This Subsystem Design Requirement document is a development specification that establishes the performance, design, development, and test requirements for the Alignment subsystem (WBS 1.7.1), Beam Diagnostics (WBS 1.7.2), and the Wavefront Control subsystem (WBS 1.7.3) of the NIF Laser System (WBS 1.3). These three subsystems are collectively referred to as the Beam Control \& Laser Diagnostics Subsystem. The NIF is a multi-pass, 192-beam, high-power, neodymium-glass laser that meets requirements set forth in the NIF SDR 002 (Laser System).

\subsection{Applicable Documents}

This section lists DOE orders, codes, and standards which are applicable to the NIF Beam Control \& Laser Diagnostics Subsystem. The applicable portions of these documents apply. Applicable LLNL standards are considered contingent upon the decision of final site selection.

\subsection{Applicable NIF Documents}

The following NIF Project Documents apply to the Beam Control \& Laser Diagnostics Subsystem as specifically referenced in later sections.

\subsubsection{Applicable NIF Project Documents}

National Ignition Facility Functional Requirements and Primary Criteria, Revision 1.4, L-15983-3, February, 1996

National Ignition Facility System Design Requirements, Laser System SDR002, Revision A, NIF-LLNL-96-228, L-21707-01

“Proposed Metrication Policy for NIF," R. Sawicki, NIF-LLNL-96-038, L-21248-01, 21 January, 1996

NIF Grounding Plan, NIF-LLNL-94-211, L-17346-1

NIF-LLNL-93-044/L-15958-1, National Ignition Facility Quality Assurance Program Plan, November 1993

NIF-LLNL-94-017/L-15958-5, NIF Ancillary Software Quality Assurance Plan, January 12, 1994

NIF Procedure 1.6 : Assignment of Quality Levels

\subsubsection{Applicable NIF Drawings}

The following NIF Project drawings apply as specified in sections 3.2 to 3.6. The specified revision applies.

AAA-96-104900-0B, Final Optics Assembly

AAA-96-104905-0A, Layout, Beam Transport Configuration

AAA-96-100596-0B, LTAB NIF Optics Main Laser Optic System, 7/19/96

Parsons Drawing No CFG-201, "LTAB, Floor Plan at Level -0"', 4/16/96

\subsubsection{Interface Control Documents}

Interface requirements between WBS level 1.7.1, 1.7.2, \& 1.7.3 and other subsystems are controlled through separate Interface Control Documents (ICDs).

\subsection{Applicable US Government Codes and Standards}

\subsubsection{DOE Orders}

- 420.1 - Facility Safety

- DOE Order 5700.6C, Quality Assurance 


\subsubsection{Other Government Regulations}

- 29 CFR 1910_-Occupational Safety and Health Act (OSHA)

- 29 CFR 1910.7 Definitions and Requirements for a Nationally Recognized Testing Laboratory (NRTL)

- FED-STD-209E-Airbome Particulate Cleanliness Classes in Cleanrooms and Clean Zones

\subsection{Applicable National Codes and Standards}

The following National Consensus Codes and Standards are specifically referenced elsewhere in this document, and are applicable to the beam control \& laser dianostic subsystems.

- American National Standards Institute (ANSI):

- ANSI Z136.1 - 1993, Laser Safety

- DOE-STD-1020-94, Natural Phenomena Hazards Design and Evaluation Criteria fơr DOE Facilities

- American National Standards Institute (ANSI):

- ANSI MC96.1 - 1982, Temperature Measurement Thermocouples

- ANSI C2 - 1993, National Electric Code

- ANSI C84.1 - 1989, Electrical Power Systems and Equipment-Voltage Rating (60 HZ)

- American Society for Testing and Materials (ASTM):

- ASTM A325 - 1994, Standard Specification for High Strength Bolts for Structural Steel Joints

- ASTM A449 - 1993, Standard Specification for Quenched and Tempered Steel Bolts and Studs

- ASTM A490 - 1993, Standard Specification for Heat-Treated Steel Structural Bolts, 150 ks Minimum

Tensile Strength

Recommendations

- UCRL 53526 Rev 1 - Natural Phenomena Hazards Modeling Project for Department of Energy Sites (1985)

- UCRL 53582 Rev 1 - Natural Phenomena Hazards Modeling Project for Department of Energy Sites (1984)

- DOE-STD-1021-93, Natural Phenomena Hazards Performance Categorization Guidelines for Structures, Systems, \& Components.

\subsection{Applicable LLNL Standards}

Pending final site selection, the following LLNL standards generally apply to NIF, and are assumed to apply to the alignment subsystem until determined otherwise.

LLNL M-010, March 1989, "Health and Safety Manual"

LLNL, M010, "Hazards Control Manual"

LLNL M-012 Rev 7, Feb. 1993, "Design Safety Standards -Mechanical Engineering"

LLNL, M-256 "Mechanical Engineering Design Practice"

\subsection{Subsystem Description and Characteristics}

\subsection{Subsystem Definition}

The beam control \& laser diagnostics subsystem provides an automatic beam characteristic measurement and system adjustment function such that the NIF can meet its alignment and optical quality specifications. 


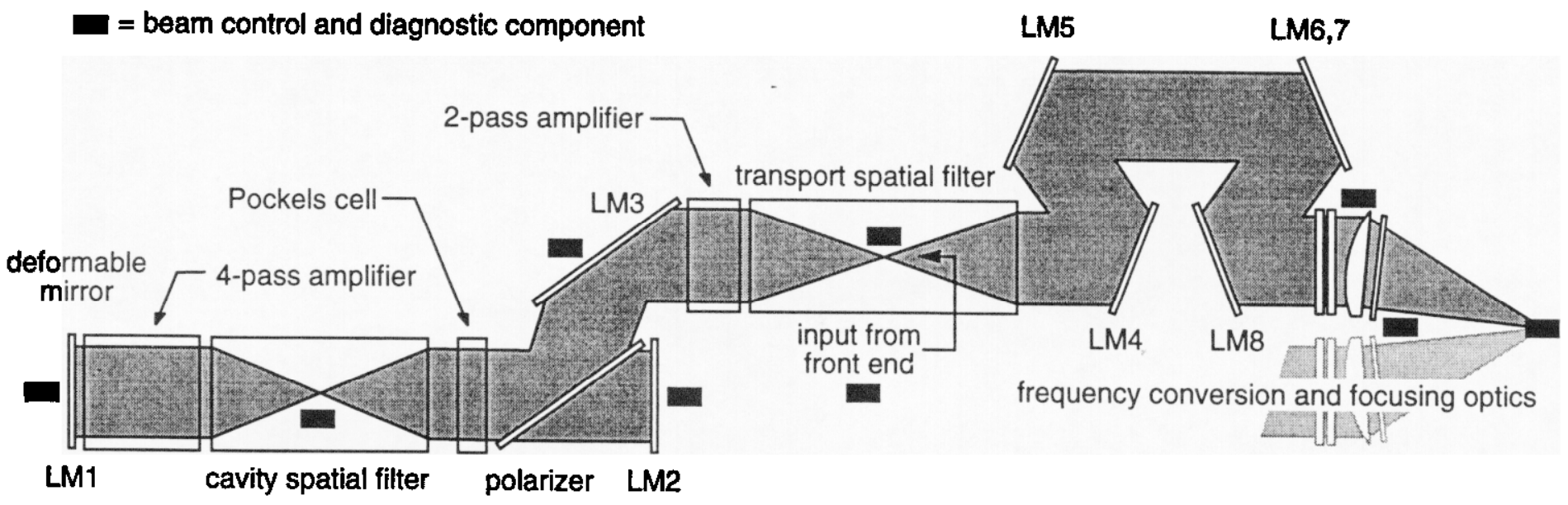

Figure 3.1 : Location of the beam control \& diagnostic components in the laser chain

\subsubsection{Subsystem Description}

The NIF Laser System is composed of 192 individual beams which must be individually conditioned and collectively positioned. The beam control \& laser diagnostics subsystem comprise optical, mechanical, electronic, control, and data processing components that measure beam energy, power, spatial intensity distribution, position, direction, size, and wavefront in key locations; calculate errors in wavefront, alignment or focus; and implement automatic adjustments of beam transport components to bring the errors within tolerance.

In general, the alignment systems must establish and maintain the correct relationships between beam position, beam angle, laser component clear apertures, and the target. At the target this includes adjustment of beam focus to obtain the correct spot size. This must be accomplished on all beams in a time consistent with planned shot rates. Components required for installation, activation, and initial operation independent of control from the integrated control systems are also included.

Accurate measurement of beam characteristics is important for proper modeling of target experiments since target performance is very sensitive to details of its irradiation. To the extent possible, it is desirable to measure the properties of each beam going to the target on each target shot.

Processing of the data collected on each shot must be accomplished quickly enough to provide feedback for adjustment prior to the next shot at the maximum shot rate.

Optimization of the wavefront for each shot is based partly on current information and partly on information from previous shots. Correction for static errors due to fabrication, slowly varying thermally induced errors, and errors due to gradients in the gas path through which the beam is propagating is based on real-time measurement in the period before a shot. Correction for amplifier aberrations induced at shot time is based on measurements of these effects from previous shots.

\subsubsection{Subsystem Functions}

Beam Control and Laser Diagnostics functions

- Establish and maintain the correct relative position and angle of beams, component clear apertures, and the target. At the target, this includes adjustment of beam focus to obtain the correct spot size. This must be accomplished on all beams in a time consistent with planned shot rates.

- Characterize the performance of the laser system, the light delivered to the target, and the light scattered back into 
the final focus lens from the target. The parameters to be measured are determined by laser operating requirements and target irradiation requirements.

- Establish and maintain wavefront quality sufficient for efficient performance of the frequency conversion crystals and for proper illumination of the target.

- The above functions include the optical, mechanical, electronic, and control components required for installation, activation, and initial operation independent of control from the integrated control systems.

- Provide stand-alone capability for classified target alignment to the extent that additions are required to the unclassified systems

\subsubsection{Subsystem Diagrams}

Heavily shaded items in Fig 3.1.3 are specific beam control and laser diagnostics (BCD) components, and lighter shading indicates beam line hardware containing BCD components or having specific BCD requirements.

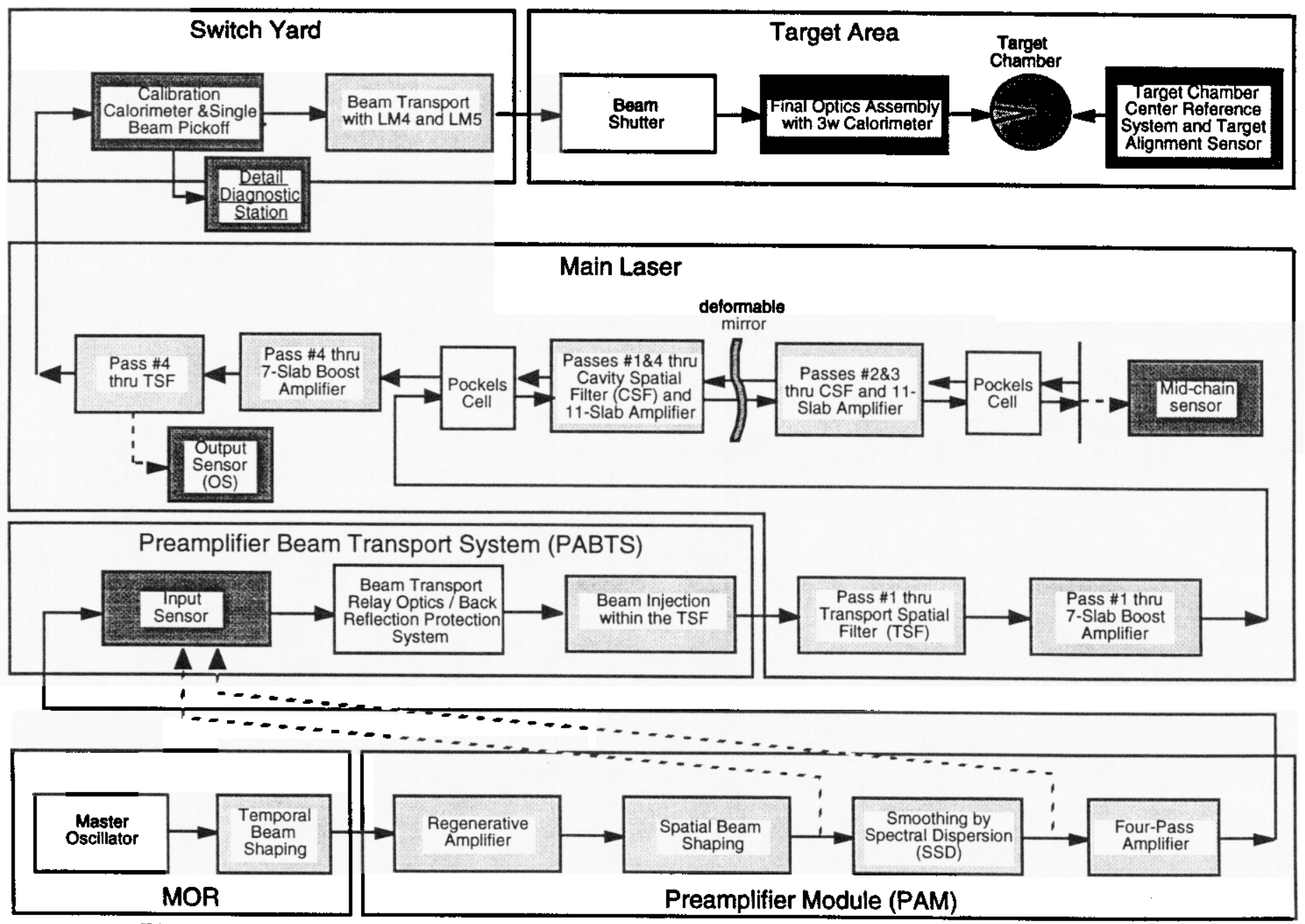

Fig 3.1.3 : Beam Control and Diagnostics Block Diagram

\subsubsection{System Operating Modes}

Figure 3.1.3.1 identifies the sequence of operating modes planned for the NIF facility. The laser system will also operate in all these modes, following the same scenario as the overall facility. The beam control \& laser diagnostics subsystem can be operated in the following modes. 


\section{First Item Test}

Beam control \& laser diagnostics subsystem components will be produced from production drawings and assembled to verify component and system functionality prior to approving complete production.

\section{Subsystem and Component Debug during Assembly}

Components and line-replaceable units within a the beam control \& laser diagnostics subsystem can be individually acceptance tested before system assembly.

\section{Commissioning and Acceptance Testing}

During commissioning and acceptance testing, the elements of the beam control \& laser diagnostics subsystem can be individually operated or operated together.

\section{Normal Operation}

The minimum energized unit is a $4 \times 2$ bundle of the laser chain. Bundles can be operated independently. Clusters can be operated independently.

Laser Bays can be operated independently.

\section{Maintenance}

Beam control \& laser diagnostics subsystem maintenance can only occur in a Laser Bay that is in a safe state.

During maintenance the beam control \& laser diagnostics subsystem will conform to NIF maintenance schedules.

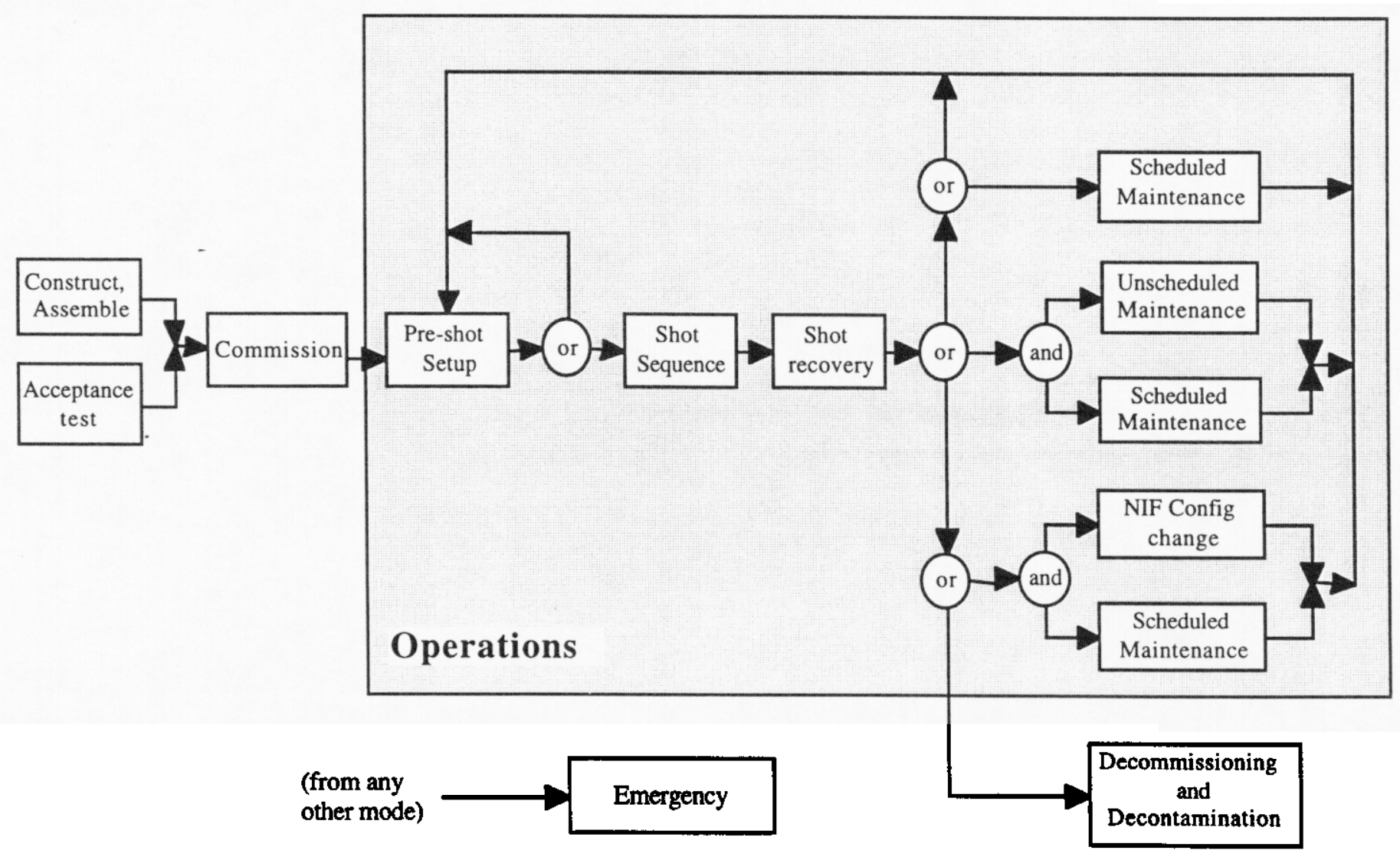

Figure 3.1.3.1 : NIF operating modes specify the System Control operating modes 


\subsubsection{Interfaces}

The principal functional and physical interfaces for the beam control \& laser diagnostics subsystem are:

\section{WBS 1.1.5 System Integration}

The beam control \& laser diagnostics subsystem must conform to the Laser Bay General arrangement drawings. In turn, these drawings must provide the location of the sensors and actuators, and sufficient space to assemble, install and service them.

\section{WBS 1.2.2.1 Laser Building}

The beam control \& laser diagnostics subsystem resides in the Laser building. The building must have sufficient corridor size to allow easy transport of the largest line replaceable unit in a time that allows achievement of the required maintenance intervals.

The combination of the laser building, the support structures and the beam control \& laser diagnostics components must not amplify vibrations from any source to a level that degrades performance. Incidental power and lighting must be available to the regions of the beam control \& diagnostics to allow assembly, installation and servicing. Local temperature and humidity excursions must not affect performance.

\section{WBS 1.2.2.3 Optics Assembly Building}

The optics assembly building must be capable of assembling and cleaning and packaging beam control \& laser diagnostics components for transport into the LTAB.

\section{WBS 1.2.3 Support Facilities}

During component inspection, acceptance testing, assembly, installation and maintenance the system will utilize support facilities.

\section{WBS 1.3.1 Optical Pulse Generation System}

The optical pulse generation system provides the input spatial pulse to be aligned and diagnosed.

\section{WBS 1.3.2 Amplifier System}

Beam control functions cannot be initiated until the amplifiers have sufficiently cooled so as to minimize dynamic thermal distortions during and after alignment and wavefront optimization.

\section{WBS 1.4.1.3 Laser Bay Beam Enclosures}

The beam control \& laser diagnostics subsystem interfaces with the laser enclosures all along each beamline. The interface must be leak tight, must not transport vibration, must be structurally independent and must be capable of clean assembly. Both elements are adequately clean for beam operation and do not contaminate one another in operation, during maintenance or in-situ cleaning.

\subsubsection{Beam control \& Laser Diagnostics Subsystem Components}

The beam control \& laser diagnostics subsystem consists of the following major components:

Input sensor

Beam forming aperture

Multipass preamp spatial filter pinhole mechanism

Optics inspection light source/ alignment laser

LM1 deformable mirror

Cavity spatial filter pinhole, reticle, and viewing mechanisms

Mid-chain sensor

LM3 centering reference

Transport spatial filter pinhole, reticle, and viewing mechanisms

Transport spatial filter diagnostic pickorr components

Output sensor and related transport components

High bandwidth detector multiplexing module

Focal plane diagnostic station(s) and related beam transport

Optics inspection system 
1w calibration calorimeter

Final optics laser diagnostics

Pulse synchronization/ cross-timing system

Target alignment sensor

Chamber center reference system

Target backscatter diagnostic package

Alignment, beam diagnostics, and wavefront correction FEPs

\subsection{Requirements and Verification}

The requirements that the beam control \& laser diagnostics subsystem must meet are included in sections 3.2 through 3.6 below. The requirements defined by systems interfacing with the beam control \& laser diagnostics subsystem are defined in ICD's with each of the elements listed in section 3.1.4.

\subsubsection{Performance Characteristics}

\subsubsection{Beam Control Requirements}

\subsection{Adjust Pulse Timing}

Measure pulse arrival times at target chamber center to support adjustments of individual beam path lengths for simultaneous arrival of OPG short pulses to within 30 psec. As a design goal, simultaneity measurements for a bundle should be made within the specified no-yield shot-turn around time with the capability to measure all beams as part of the weekly scheduled maintenance day.

\subsection{Adjust Beam Intensity}

Adjust the relative position of the beam shaper/apodizer and the regenerative amplifier output beam to minimize the difference between measured and desired spatial beam intensity profiles.

Spatial and intensity resolution of measurement shall be better than $1 \%$ of beam dimension and $2 \%$ of maximum beam intensity respectively.

\subsection{Identify Beam Shaper/apodizer Center}

Identify the center of the beam shaper/apodizer to better than $0.6 \%$ of apodizer aperture by remote insertion of a near-field reference.

\subsection{Adjust Beam Center}

Accomplish centering adjustments such that the centerline (CL) of the pulsed beam is matched to the center of pupil plane optics in the multipass preamp, the cavity spatial filter (SF), the transport SF, and the final optics assembly to less than $0.5 \%$ of the beam dimension.

\subsection{Adjust Beam Rotation}

Accomplish apodizer rotation in the pulse generation system and beam rotation in the target area to match the beam orientation with the orientation of amplifier and final optics apertures to less than 5 mrad.

\subsection{Provide Pinhole Centering}

Point beam to center of shot pinhole locations with an accuracy of better than $5 \%$ of the pinhole diameter.

\subsection{Correct Wavefront Errors}

Correct beam wavefront errors with a 39 actuator deformable mirror to maintain low spatial frequency angle deviation within the $1 \mathrm{w}$ laser output beam at $\leq 20 \mu \mathrm{rad}$ for the normal range of thermal conditions at the time of a shot.

The deformable mirror shall be capable of correcting simple curvature errors of \pm 15 waves when installed in the LM1 cavity mirror position. 
The wavefront correction system shall be capable of operation until $1 \mathrm{sec}$ before firing the laser and operate with a bandwidth of $\geq 1 \mathrm{~Hz}$.

\subsection{Provide Target Position Reference}

Provide a stable position-reference-system in the target bay for repeatable positioning of targets with respect to narrow field of view (FOV) target diagnostics. System resolution shall be $\leq 10 \mu \mathrm{m}$ and the long term stability shall be $\leq 30 \mu \mathrm{m}$. Long term drifts in the position-reference system will require realignment of the sensor with critical target diagnostics which are sensitive to the field of view.

The position-reference-system shall operate over a region within $5 \mathrm{~cm}$ of nominal target chamber center.

\subsection{Provide Beam Positioning}

Position beams in the target plane for each shot such that the rms deviation of all beams from their specified positions at the target plane or its equivalent is 50 micrometers $(\mu \mathrm{m})$ or less. No single beam shall deviate more than $200 \mu \mathrm{m}$.

Accuracy of surrogate alignment shall be periodically validated by direct detection of low level pulses.

Position beams on equitorial target-backlighter targets with deviation $\leq \operatorname{TBD}(150 \mu \mathrm{m})$.

\subsection{Adjust Beam Focus}

Adjust final lens focus to achieve specified central lobe size in the target plane. Accuracy shall be $\pm 50 \mu \mathrm{m}$ in lobe size over a focus range of $\pm 5 \mathrm{~cm}$ relative to the nominal chamber center (no phase plate).

With a phase plate installed, the effect of focus lens adjustment will be reduced.

Accuracy shall be periodically confirmed by direct detection of low level pulses in the target plane and/or high power pulses in an equivalent plane.

\subsection{Fine Tune Frequency Conversion}

Adjust frequency conversion crystals to specified shot angle $\pm 20 \mu \mathrm{rad}$. The angle for maximum conversion efficiency is predetermined by crystal cut and operating temperature, but a range of $\pm T B D(250 \mu \mathrm{r})$ shall be accomodated for optional detuning.

\subsubsection{Laser Shot Diagnostics}

The Beam Control Systems shall perform the following additional measurements to verify performance of the Primary Criteria and Functional Requirements (specified accuracy shall be maintained down to $20 \%$ of nominal full-power laser operation)

\subsection{Measure Beam Energy}

Measure pulsed $1 w$ and $3 w$ energy (up to $2.2 \mathrm{MJ}$ ) at key locations for each beam and accurate to within $3 \%$. $\geq 97 \% 3 \mathrm{w}$ measurement shall be accomplished after the beam has passed through all of the final optic assembly components.

\subsection{Measure Beam Power}

Measure power versus time at key locations for each beam including $3 w$ output beam. Dynamic range shall exceed 50 to 1 at $3 w$ with accuracy, temporal resolution, cross-timing accuracy, and record length sufficient to achieve power balance throughout the pulse.

Specific power balance requirements may vary for different target types. To cover a likely range of such requirements, power versus time should be measured with $\leq 250$ psec rise time, $\leq 100$ psec cross-timing accuracy, $\geq 22$ ns record length, and accurate to within $4 \%$. 


\subsection{Measure Prepulse Intensity}

Measure 3w laser intensity delivered to the LEH of an ICF target during the $20 \mathrm{~ns}$ interval prior to arrival of the shaped $3 \mathrm{w}$ laser pulse. Measurement sensitivity shall be sufficient to measure less than $0.25 \mathrm{E} 8 \mathrm{~W} / \mathrm{cm} 2$.

\subsection{Measure Pulse Spot Size and Smoothness}

Measure laser pulse spot size and smoothness in the target plane or its equivalent with resolution and field of view sufficient to verify target irradiation characteristics with $30 \mu \mathrm{m}$ spatial resolution and $10 \mathrm{psec}$ temporal resolution.

\subsection{Measure Beam Wavefront}

Measure output $1 \mathrm{w}$ wavefront on each beam sampled at approximately $1 / 2$ the actuator spacing of the deformable mirror with an accuracy of 0.1 waves.

\subsection{Image Beam in FCC Plane}

Measure near-field image of the $3 \mathrm{w}$ beam in the frequency conversion crystal plane with spatial resolution of 2.7 $\mathrm{mm}(1 / 150$ of the beam dimension).

\subsubsection{Detect Optical Damage}

Inspect chain optical components for damage. Defects $\geq 0.5 \mathrm{~mm}$ should be detected. Detection of flaws $\geq 25 \%$ of the critical size in vacuum loaded components shall be achieved for protection of equipment.

The frequency of such inspections will be based on operating experience with the goal that optics inspections become a part of weekly maintenance.

\subsubsection{Cleanliness}

\subsection{Internal metal component cleanliness}

The cleanliness of all beam control \& diagnostics metal surfaces exposed to the beam enclosure enviroment shall be maintained at a surface cleanliness level as defined by MIL-STD-1246C Level 100.

\subsection{Assembly cleanliness}

The beam control \& diagnostics components that are located in main beam enclosures shall be precision cleaned and assembled in a Class 100 clean room environment, per FED-STD-209D.

During operation of the laser, the optical elements of the laser shall be maintained at a surface cleanliness level as defined by MIL-STD-1246C - Level 50.

Permissible cleanliness degradation shall be budgeted across the assembly, measurement, transport, storage, installation and operation phases of laser construction

\subsection{External surface cleanliness}

The cleanliness of external surfaces of the beam control \& diagnostics components should be cleaned TBD to class 100,000 clean room conditions. If feasible the surface should be designed and constructed for Class 10,000 clean room use and shall be compatible with cleaning by aqueous solution.

\subsubsection{Shot turn-around time}

The shot turn-around time for Laser System shall be no more than 8 hours for no yield shots. The Laser System shall not preclude future upgrade to achieve a shot turn-around time of 4 hours for no yield shots. The shot turnaround time is defined as the minimum time required after a full-system, no-fusion-yield shot until the next shot can be taken.

To comply with the system turn-around time the beam control \& diagnostics subsystem shall operate in an automatic mode with provision for full operator oversight and optional intervention. Preparations for each shot shall take TBD (1 hour) or less after waiting an appropriate time for the amplifiers to cool. 


\subsubsection{Experiment Compatibility}

\subsection{Accomodate classified experiments}

Alignment to classified targets shall be accomplished by switching the associated target images to a classified area during target positioning.

\subsection{Future Upgrades for Other Users}

\subsection{Future Additional Target Chamber}

The design of the Laser System shall not preclude the future installation of an additional target chamber, employing all laser beams, for weapons physics and/or radiation effects testing. As a part of the NIF project, the Laser System, in concert with other NIF systems, shall provide a general arrangementt layout for the addition of the target chamber. All Laser System designs shall be compatible with this design concept. All structural elements shall provide clearance for the identified future laser beam paths. Certain structures, such as building skins or shielding walls, require integrity to fulfill their functions prior to addition of the future target chamber; clearance for future beams is not required through such structures. However, their design shall be adequate that they will meet their requirements after addition of the future target chamber and associated beam clearances.

\subsection{Radiation Effects Testing Capability}

The baseline Laser System design shall incorporate basic capabilities so as not to preclude radiation effects testing by DNA or DOE, with future upgrade.

\subsection{Other User Needs}

As a design goal, the Laser System should accommodate requirements of other users with diverse needs.

\subsubsection{Physical Characteristics}

\subsubsection{General Arrangement}

\subsection{Beam Control \& Diagnostics Subsystem Architecture}

The beam control \& diagnostics subsystem shall incorporate the following basic architecture:

a. input sensor and related components to align and characterize the optical pulse generation part of the laser

b. midchain sensor to characterize the beam after two full passes through the main laser chain

c. deformable mirror with 39 actuators within the main amplifier and spatial filter part of the laser

d. output sensor to align and characterize the multipass amplifier and spatial filter part of the laser

e. 3w calorimeter within the final optics assembly

f. target and beam alignment instruments in the target chamber part of the system

g. illumination and calibration instrumentation for occasional use

\subsection{General Arrangement Drawings}

The beam control $\&$ diagnostics subsystem shall conform to the following drawings indicated in section 2.1.2 which specify the general arrangement.

\subsubsection{Beam Control \& Diagnostics Subsystem General Configuration}

\subsection{Number of Total Beams}

The beam control \& diagnostics subsystem shall be configured to process 192 simultaneous beams.

\subsubsection{Isolation and Grounding}

Each beam control \& diagnostics assembly shall be electrically isolated from its surroundings when installed in the LTAB to assure the success of the single point ground. 


\subsubsection{Reliability, Availability, Maintainability}

\subsubsection{Lifetime}

The beam control \& diagnostics subsystem shall operate for 30 years.

\subsubsection{Replaceability}

Any portion of the beam control \& diagnostics subsystem which cannot reasonably be designed for 30 year lifetime shall be designed to be replaced or repaired at reasonable cost in a timely manner consistent with the overall availability of the beam control \& diagnostics subsystem as stated in 3.2.3.3 and 3.2.3.5. The following components are line replaceable units:

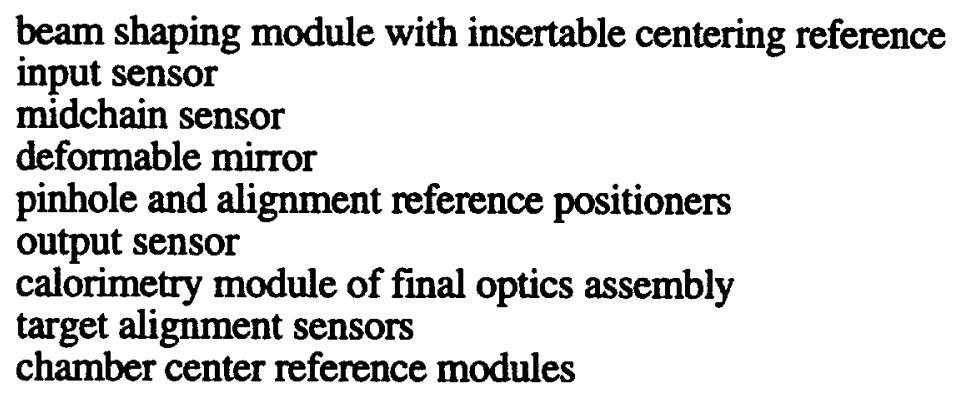

Interchangeability of beam control \& diagnostics subsystem components shall be preserved. All components with the same part number shall be interchangeable.

\subsubsection{Inherent Availability}

The beam control \& diagnostics subsystem shall have a shot availability of at least $99.20 \%$. The system is unavailable when it is undergoing unplanned maintenance. Unplanned maintenance includes failure detection and active repair as well as logistic and administrative downtimes.

\subsubsection{Reliability}

The beam control \& diagnostics subsystem shall have an overall reliability of $94.93 \%$. Reliability is defined as the probability of meeting the minimum requirements of the experiment per no-yield shot as stated in SDR2:3.2.3.4.

\subsubsection{Maintainability}

The beam control \& diagnostics subsystem shall have a scheduled maintenance plan that fits within an overall annual plant goal of 69 days. The unplanned maintenance goal is 51 hours per year. Opportunistic maintenance activities are performed between shots and during other system downtimes.

\subsubsection{Recovery From Abnormal Events}

The time required for the beam control \& diagnostics subsystem to recover from any abnormal event shall be less than the maximum times cited below, as a function of the expected yearly frequency of occurrence of the event.

$$
\begin{array}{cc}
\text { Expected Frequency of Occurrence Per Year, } F & \text { Maximum Recovery Time } \\
1 \mathrm{~F} \geq 1 & 24 \text { hours } \\
1 \mathrm{~F}>1 \mathrm{E}-2 & 1 \text { week } \\
1 \mathrm{E}-2>\mathrm{F} \geq 5 \mathrm{E}-4 & 3 \text { months }
\end{array}
$$

Probabilities listed in DOE-STD-1020-94 shall be used for natural phenomena.

\subsubsection{Environmental}

The site for NIF has not yet been selected. The present design is therefore non-site-specific. For the purpose of Title I design of the Laser System, it shall be assumed that NIF will be constructed at a site with the general infrastructure as available at candidate sites. Specific environmental assumptions are listed in the following sections. 


\subsubsection{Ambient Temperature/Humidity}

All beam control \& diagnostics subsystem components within the Laser Building shall meet all requirements when operated at a temperature of $20 \mathrm{C} \pm 0.3 \mathrm{C}$, a relative humidity of $30 \%$ to $60 \%$, and a pressure equal to ambient atmospheric pressure $\pm 10 \mathrm{~cm}$ water (to accommodate positive/negative air systems). Any components normally operated outside the LTAB Building shall meet all requirements when operated between -4.4 C (dry bulb, winter) and $20.6 \mathrm{C}$ (wet bulb, summer) or $37.8 \mathrm{C}$ (dry bulb, summer), and local atmospheric pressure.

\subsubsection{Ambient Cleanliness}

The beam control \& diagnostics subsystem shall meet all requirements when operated within the NIF LTAB. The ambient cleanliness levels in pertinent areas of the LTAB are as follows:

Area Ambient Cleanliness Class

Laser Bay 100,000

Switch yard 100,000

Target Bay 100,000

MOR 100,000

\subsubsection{Ambient Vibration Environment}

The beam control \& diagnostics subsystem shall meet all requirements, while being exposed to ambient random vibration of $10-10 \mathrm{~g} 2 / \mathrm{Hz}$, from 1 to $200 \mathrm{~Hz}$, applied at the special-equipment mounting surface of the foundation of the Laser or Target Area building.

\subsubsection{Back-Reflected Light}

The beam control \& diagnostics subsystem shall perform consistent with the following statement.

"The Laser System shall be resistant to major damage from back-reflected or scattered light."

The effect on the beam control \& diagnostics subsystem is TBD.

\subsection{Design and Construction}

\subsubsection{Hazard Classification}

The NIF shall be designed and operated as a low-hazard, non-nuclear facility. The inventory of key radionuclides shall not exceed the limits defined in the Preliminary Hazards Analysis, and cited below.

\subsubsection{Natural Hazards Classification}

Laser subsystems shall meet the performance class 2 (PC2) design goals in DOE-1020.

\subsubsection{Radiation Protection}

The beam control \& diagnostics subsystem does not produce any radionuclides and therefore is not bound to an associated requirement.

\subsubsection{Safety}

The beam control \& diagnostics subsystem shall be designed, constructed, and operated as part of the NIF such that it is a low-hazard, radiological component of the NIF. Compliance with this classification shall be verified through a Preliminary Hazard Analysis assessment of bounding accidents involving those radionuclides and/or chemicals presenting the most significant hazards (see DOE Order 5481.1B, Safety Analysis Review System). Administrative controls shall be established prior to CD3 to ensure that inventory limits for a radiological lowhazard, non-nuclear facility are not exceeded.

Unless otherwise specified herein, all elements of the amplifier subsystem shall meet the requirements of the LLNL Mechanical Engineering Design Safety Standards, Electrical Engineering Design Standards, and Laser safety standards. 


\subsubsection{Life Safety}

Life Safety shall comply with DOE Order 420.1 , Facility Safety. The beam control \& diagnostics subsystem shall not compromise adequate means of egress, protection of vertical openings, travel distances, capacities, and emergency lighting.

\subsubsection{Laser Safety}

The beam control \& diagnostics subsystem within the laser bay shall comply with requirements of ANSI Z136.1 regarding laser safety. All primary laser paths shall have laser shutters to isolate particular sections of the laser system from illumination by operational beams. Exposure to hazardous levels of laser light shall be prevented by the use of physical barriers, personnel training, interlocks, and personnel entry controls. Protective equipment, such as laser goggles, shall be used within the laser bay when necessary and feasible for operational purposes. Interlock systems shall be dedicated within the laser bay and designed to activate laser shutters or deactivate laser systems if access doors are opened. Requirements of this paragraph also apply to systems within the laser bay that are required to protect workers from hazardous exposure to laser light from other systems.

\subsubsection{Occupational Safety}

Industrial hygiene and occupational safety shall comply with 29 CFR 1910 and DOE Order 440.1, Worker Protection Management for DOE Federal and Contractor Employees.

Construction safety shall comply with the requirements of 29 CFR 1926, OSHA and DOE Order 440.1, Worker Protection Management for DOE Federal and Contractor Employees.

Facility subsystems (e.g., vacuum systems, nitrogen supply, etc.) shall be designed to default to a safe state upon loss of power.

\subsubsection{Fail-Safe Design}

Wherever reasonably possible, Laser Systems shall be designed to fail safe upon inadvertent loss of power, accidental breach of isolated areas, or other failure.

\subsubsection{Future Modifications and Upgrades}

As a design goal, the Laser System shall provide for future reconfiguration and modification at minimum cost and with minimum effect on the overall operation of the facility.

\subsubsection{Decontamination and Decommissioning}

The beam control \& diagnostics subsystem shall include considerations to allow cost effective future decontamination and decommissioning (D\&D) of all structures and equipment.

\subsubsection{Human Factors}

The beam control \& diagnostics subsystem shall be designed in an ergonometric fashion to ensure that human reliability during operation and maintenance is sustained at a level consistent with meeting overall availability and reliability objectives. Consistency in displays, warnings, and human interfaces should be maintained throughout the Laser System and, if possible, throughout the NIF facility (i.e. GUI displays, access ports, tooling)

\subsubsection{Interchangeability}

Interchangeability of components shall be preserved as much as practical. Equipment with the same function and physical characteristics shall be interchangeable. Components of the same drawing number or the same part number shall be interchangeable. Procurement specifications of components shall indicate the degree of interchangeability required.

\subsubsection{Documentation and Records}

The beam control \& diagnostics subsystem shall provide sufficient documentation to comply with the NIF Quality Assurance Plan, and DOE Order 5700.6C, Quality Assurance, Criterion-4 Documents and Records, which states: "Documents shall be prepared, reviewed, approved, issued, used and revised to proscribe processes, specify 
requirements or establish design. Records shall be specified, prepared, reviewed approved and maintained."

Examples of documents that should be controlled include drawings, data files, calculations, specifications, computer codes, purchase orders, vendor supplied documents, procedures, work records and data sheets and test records. Revisions should be reviewed by the organizations that originally prepared and approved the documents. Controlled documents should be distributed to those doing the work.

\subsubsection{Design Processes}

Design shall be carried out using sound engineering principles and appropriate standards. Design work including changes shall incorporate applicable requirements and design bases. Interfaces shall be identified and controlled. The adequacy of design products shall be verified or validated by qualified individuals other than those who did the work. Verification and Validation work shall be completed before approval and implementation of the design.

\subsubsection{Supervisory Software Access to Distributed Control Points}

The beam control \& diagnostics subsystem shall include a control system with interface to the NIF ICS. The control system shall be designed to provide remote and local control functions required for normal operation and maintenence.

Access to all distributed control points that are integrated into the control system shall be made by Front End Processors that implement the hardware-level interface to the control points. The FEP software shall implement those functional requirements that are determined by requirements analysis to be allocated to the FEP layer in the controls architecture. The requirements analysis shall be guided by the physical properties and performance constraints of the control hardware, and by those operational scenarios requiring operation independent of the supervisory software or locality of control.

\section{$3.4 \quad$ Logistics}

\subsubsection{Spare Equipment}

As a part of the design/construction project, the beam control \& diagnostics subsystem shall provide an initial complement of spare parts as required to activate the system.

\subsubsection{Maintenance Equipment}

As a part of the design/construction project, the beam control \& diagnostics subsystem shall provide all equipment required to inspect, service, and maintain itself to meet the maintainability and availability requirements in $\$ 3.2 .3$. Maintenance equipment shall include all handling fixtures, lifting equipment, cleaning equipment and other special tools not otherwise available within NIF, that are necessary to perform any planned (scheduled or unscheduled) maintenance activity

\subsection{Quality Assurance}

\subsection{Q-Level Assigned}

\begin{tabular}{|c|c|c|c|c|c|}
\hline \multirow[t]{2}{*}{$\begin{array}{l}\text { WBS } \\
\text { element } \\
\text { number }\end{array}$} & \multirow[t]{2}{*}{ WBS element title } & \multicolumn{3}{|c|}{$\begin{array}{c}\text { Assigned } \\
\text { Q-level }\end{array}$} & \multirow[t]{2}{*}{ Why not Q-level 3 ? } \\
\hline & & 1 & 2 & 3 & \\
\hline 1.7 .1 & Alignment Systems & & & & \\
\hline 1.7.1.1 & Pulse Generator Alignment & & & $\sqrt{ }$ & \\
\hline 1.7 .1 .2 & Main Laser Alignment & & & $\sqrt{ }$ & \\
\hline 1.7 .1 .3 & Target Area Alignment & & & $\sqrt{ }$ & \\
\hline 1.7.1.4 & Alignment Control & & $\sqrt{ }$ & & $\begin{array}{l}\text { Automatic alignment of all } \\
\text { beamlets is critical to satisfy } \\
\text { NIF pointing stability and laser }\end{array}$ \\
\hline
\end{tabular}




\begin{tabular}{|c|c|c|c|c|c|}
\hline & & & & & spot size requirements. \\
\hline 1.7 .2 & Beam Diagnostics & & & & \\
\hline 1.7 .2 .1 & Pulse Generator Diagnostics & & & $\sqrt{ }$ & \\
\hline 1.7 .2 .2 & Main Laser Diagnostics & & & $\sqrt{ }$ & \\
\hline 1.7 .2 .3 & Target Area Diagnostics & & $\sqrt{ }$ & & $\begin{array}{l}\text { This element contains the laser } \\
\text { damage detection system. } \\
\text { Failure of this system to perform } \\
\text { as designed could have } \\
\text { significant } \\
\text { cost/schedule/performance } \\
\text { impacts due to undetected } \\
\text { damage that propagates in the } \\
\text { optical system }\end{array}$ \\
\hline 1.7 .2 .4 & Energy Diagnostics Data System & & & $\sqrt{ }$ & \\
\hline 1.7 .2 .5 & Power Diagnostics Data System & & & $\sqrt{ }$ & \\
\hline 1.7 .2 .6 & Image Diagnostics Data System & \multicolumn{4}{|c|}{ Not applicable, work has been transferred to 1.5} \\
\hline$\overline{1.7 .2 .7}$ & $\begin{array}{l}\text { Roving Mirror and Diagnostics } \\
\text { Positioning System }\end{array}$ & & & $\sqrt{ }$ & \\
\hline 1.7 .3 & \multicolumn{5}{|l|}{ Wavefront Control Systems } \\
\hline$\overline{1.7 .3 .1}$ & Adaptive Optics & & $\sqrt{ }$ & & $\begin{array}{l}\text { Optimization of wavefront } \\
\text { quality is critical to satisfy NIF } \\
\text { operating power and power } \\
\text { balance requirements. }\end{array}$ \\
\hline 1.7 .3 .2 & Wavefront Measurement & & & $\sqrt{ }$ & \\
\hline 1.7 .3 .3 & Wavefront Control Systems & & & $\sqrt{ }$ & \\
\hline 1.7 .4 & Laser Control Integration & \multicolumn{4}{|c|}{$\begin{array}{l}\text { Not applicable, during Title I Q-levels for Laser Control } \\
\text { Integration will be the same as determined for System } \\
\text { components. }\end{array}$} \\
\hline 1.7.4.1 & Project Management and Planning & 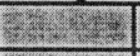 & 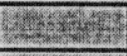 & 5.7x+8. & 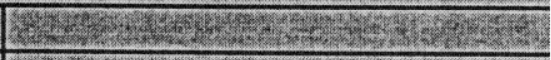 \\
\hline$\overline{1.7 .4 .2}$ & $\begin{array}{l}\text { Reliability / Availability / } \\
\text { Maintainability }\end{array}$ & & & 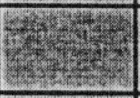 & 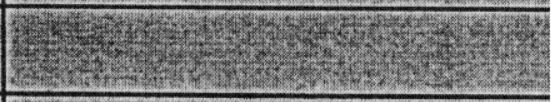 \\
\hline 1.7 .4 .3 & Assurances / ES\&H & 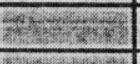 & 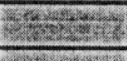 & 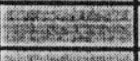 & 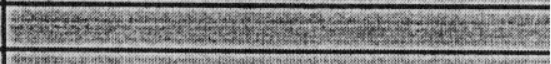 \\
\hline 1.7 .4 .4 & Requirements / Interface Control & 205 & 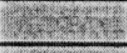 & 5 & 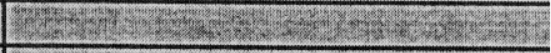 \\
\hline 1.7 .4 .5 & System Engineering & 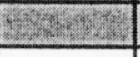 & $8+25$ & \begin{tabular}{|c|}
346 \\
\end{tabular} & 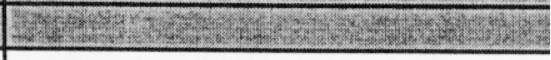 \\
\hline & & & & & \\
\hline & & & & & \\
\hline
\end{tabular}

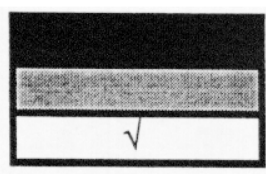

= not evaluated at this level, analysis at lower WBS level

= not applicable, either analyzed at a higher level or analysis postponed until Title II

$=$ final draft 


\subsection{Revision Record}

\begin{tabular}{|l|l|l|l|l|}
\hline Rev & Date & ECR\# & By & Description of/Reason for Change \\
\hline 0 & CDR & n/a & & \\
\hline A & $6 / 4 / 96$ & n/a & Bliss & inital Title I issue \\
\hline B & $11 / 1 / 96$ & 63 & Bliss & final Title I update, many miscellaneous changes, TBDs removed \\
\hline
\end{tabular}




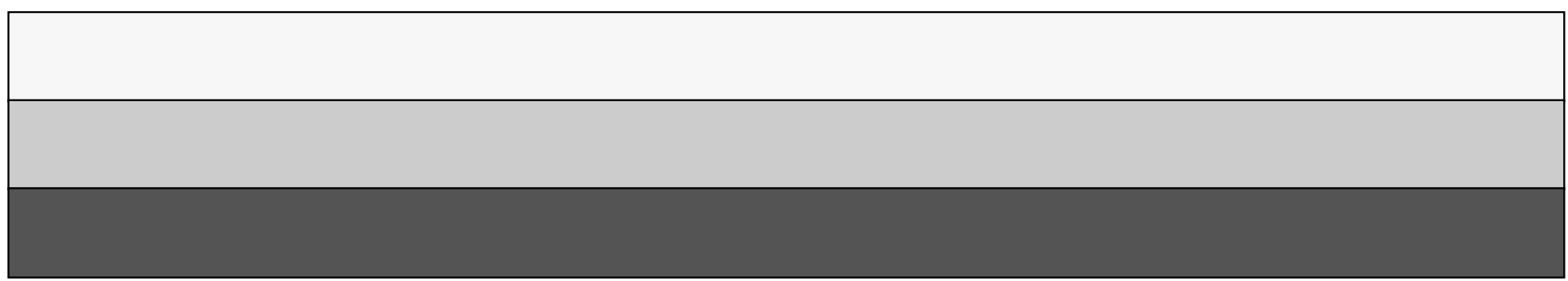

